\title{
Night-shift work and incident diabetes among African-American women
}

\author{
Varsha G. Vimalananda • Julie R. Palmer • Hanna Gerlovin • \\ Lauren A. Wise • James L. Rosenzweig • Lynn Rosenberg • \\ Edward A. Ruiz Narváez
}

Received: 15 August 2014 / Accepted: 5 December 2014 / Published online: 14 January 2015

(C) Springer-Verlag (outside the USA) 2015

\begin{abstract}
Aims/hypothesis The aim of this study was to assess shift work in relation to incident type 2 diabetes in AfricanAmerican women.

Methods In the Black Women's Health Study (BWHS), an ongoing prospective cohort study, we followed 28,041 participants for incident diabetes during 2005-2013. They answered questions in 2005 about having worked a night shift. We estimated HR and $95 \%$ CIs for incident diabetes using Cox proportional hazards models. The basic multivariable model included age, time period, family history of diabetes, education and neighbourhood socioeconomic status. In further models, we controlled for lifestyle factors and BMI.

Results Over the 8 years of follow-up, there were 1,786 incident diabetes cases. Relative to never having worked the
\end{abstract}

Electronic supplementary material The online version of this article (doi:10.1007/s00125-014-3480-9) contains peer-reviewed but unedited supplementary material, which is available to authorised users.

V. G. Vimalananda $(\bowtie)$

Center for Health Organization and Implementation Research

(CHOIR), Edith Nourse Rogers Memorial VA Medical Center (152),

200 Springs Road, Bedford, MA 01730, USA

e-mail: varsha.vimalananda@va.gov

V. G. Vimalananda $\cdot$ J. L. Rosenzweig

Section of Endocrinology, Diabetes, and Nutrition, Boston

University School of Medicine, Boston, MA, USA

J. R. Palmer $\cdot$ H. Gerlovin • L. A. Wise $\cdot$ L. Rosenberg •

E. A. Ruiz Narváez

Slone Epidemiology Center at Boston University, Boston, MA, USA

J. R. Palmer $\cdot$ L. A. Wise $\cdot$ L. Rosenberg • E. A. Ruiz Narváez Department of Epidemiology, Boston University School of Public Health, Boston, MA, USA

H. Gerlovin

Department of Biostatistics, Boston University School of Public

Health, Boston, MA, USA night shift, HRs (95\% CI) for diabetes were $1.17(1.04,1.31)$ for $1-2$ years of night-shift work, $1.23(1.06,1.41)$ for $3-$ 9 years and $1.42(1.19,1.70)$ for $\geq 10$ years $(p$-trend $<0.0001)$. The monotonic positive association between night-shift work and type 2 diabetes remained after multivariable adjustment ( $p$-trend $=0.02$ ). The association did not vary by obesity status, but was stronger in women aged $<50$ years.

Conclusions/interpretation Long duration of shift work was associated with an increased risk of type 2 diabetes. The association was only partially explained by lifestyle factors and BMI. A better understanding of the mechanisms by which shift work may affect the risk of diabetes is needed in view of the high prevalence of shift work among workers in the USA.

Keywords African-American - Black · Circadian . Diabetes $\cdot$ Shift work $\cdot$ Sleep
Abbreviations
BWHS Black Women's Health Study
FFQ Food frequency questionnaire
NHS Nurses' Health Study
SES Socioeconomic status

\section{Introduction}

Over 8 million Americans are employed in shift work [1], which is that occurring outside of typical daytime work hours. Shift workers may have working hours that change periodically or they may have a permanent work pattern that occurs at unusual times of the day, such as afternoon or night. These atypical work patterns may perturb the circadian system, which is entrained most powerfully by the solar light-dark cycle and modulates daily rhythms in alertness, core body temperature, heart rate, blood pressure and neurotransmitter 
and hormone secretion [2, 3]. Even in the short term, misalignment of endogenous circadian rhythms with the actual sleep-wake cycle leads to disrupted melatonin and cortisol secretion, decreased leptin and increased glucose and insulin [4-6]. A meta-analysis showed a modest association between shift work and vascular events [7] and there is strong evidence linking shift work to the metabolic syndrome [8-12] and obesity [13-15]. However, there are far fewer prospective data on the association between shift work and incident diabetes [16-20]. A recent meta-analysis of 12 studies found a pooled adjusted OR of 1.09 (95\% CI 1.05, 1.12) for ever having done shift work [21], highlighting the importance of better understanding how exposure to this highly prevalent, modifiable risk factor relates to the risk of diabetes.

The largest prospective cohort study to examine this relationship, the Nurses' Health Study (NHS), reported an increasing risk of incident type 2 diabetes with a greater number of years of rotating night-shift work. Among those with the longest duration of shift work, $\geq 20$ years, there was an HR of $1.58(1.43,1.74)$ for diabetes [17]. This cohort consisted of female nurses, nearly all white. Two separate longitudinal studies of male Japanese shift workers reported an adjusted OR of $1.35(1.05,1.75)$ for alternating-shift work compared with day-shift work [20], and non-significant adjusted relative risks of $1.73(0.85,3.52)$ for two-shift workers and $1.33(0.74$, 2.36) for three-shift workers as compared with fixed-shift daytime workers [19]. It is unknown whether these findings extend to other population groups.

In the USA, the prevalence of diabetes among black women $(12.2 \%)$ is more than twice that in white women $(4.5 \%)$ [22]. In the present study, we examine the relationship of night-shift work to incident type 2 diabetes among AfricanAmerican women. In the NHS, BMI explained much, but not all, of the relationship between rotating shift work and incident diabetes [17]. In a study of Swedish women [16], the association between shift work and diabetes became nonsignificant after multivariable adjustment for factors including BMI. Because black women have a particularly high prevalence of obesity, at nearly $60 \%$ [23], we examined the degree to which this risk factor explains any observed association between shift work and diabetes in our study.

\section{Methods}

Study population The Black Women's Health Study (BWHS), started in 1995, is an ongoing prospective cohort study which examines the determinants of health and disease in African-American women [24]. Participants enrolled by responding to questionnaires mailed to subscribers of Essence (a popular magazine targeted to African-American women), to members of several African-American professional organisations and to friends or relatives of early respondents. The final cohort included 59,000 women across the USA, aged 21-69 years at baseline. Follow-up questionnaires are mailed every 2 years to collect updated information including details of lifestyle factors, medication use and medical problems. After eight cycles, follow-up of the baseline cohort is $80 \%$. The institutional review boards of Boston University, Boston, MA, USA and Howard University, Washington, DC, USA approved the study protocol. All study participants indicated consent by filling out and returning baseline and follow-up questionnaires.

Questions about night-shift work were first asked on the 2005 questionnaire. The present analysis includes women who answered the night-shift work questions and who did not have diabetes at that time. Among the 34,997 women who provided adequate data for the night-shift questions, we made the following exclusions: those with diabetes in 2005 (i.e. baseline in the present analysis); those with diabetes diagnosed at age $\leq 30$ years; those with a history of cancer, myocardial infarction, stroke and/or coronary artery bypass graft surgery at baseline. This resulted in a final analytical sample of 28,041 women (Fig. 1). Women excluded from the present analyses because they did not answer the night-shift questions were similar to those who did answer the questions, with regard to age, BMI, energy intake, family history of diabetes, alcohol, coffee and soda consumption, vigorous exercise and dietary patterns. They had a higher frequency of smoking, fewer years of education and more frequently lived in a neighbourhood with low socioeconomic status (SES) (electronic supplementary material [ESM] Table 1).

Assessment of night-shift work and covariates In 2005, participants were asked if they had ever worked a night shift (graveyard shift, 00:00 hours to 08:00 hours). Women who answered affirmatively to this then reported how many years they worked the night shift. Responses were categorised (never, 1-2 years, $3-9$ years and $\geq 10$ years), as was done in a previous study among women [17]. We assessed the reproducibility of self-reported years of night-shift work among 379 BWHS participants who completed the 2005 questionnaire twice. The weighted $\kappa$ coefficient was 0.81 for the categories used in the analysis.

Current BMI $\left(\mathrm{kg} / \mathrm{m}^{2}\right)$ was calculated from adult height as reported in 1995 and current weight, which was updated in every questionnaire cycle. In a validation study of anthropometric measures conducted among 115 BWHS participants, the Spearman correlation for self-reported vs technicianmeasured weight and height was 0.97 and 0.93 , respectively [25]. Data on vigorous physical activity were obtained from the 2001 questionnaire and updated in follow-up questionnaires. Data on smoking and alcohol drinking were obtained from the baseline questionnaire for the present analysis (2005) and updated in follow-up questionnaires. Coffee and soda drinking data were obtained from the 1995 and 2001 food 
Fig. 1 Final analytical sample after exclusions

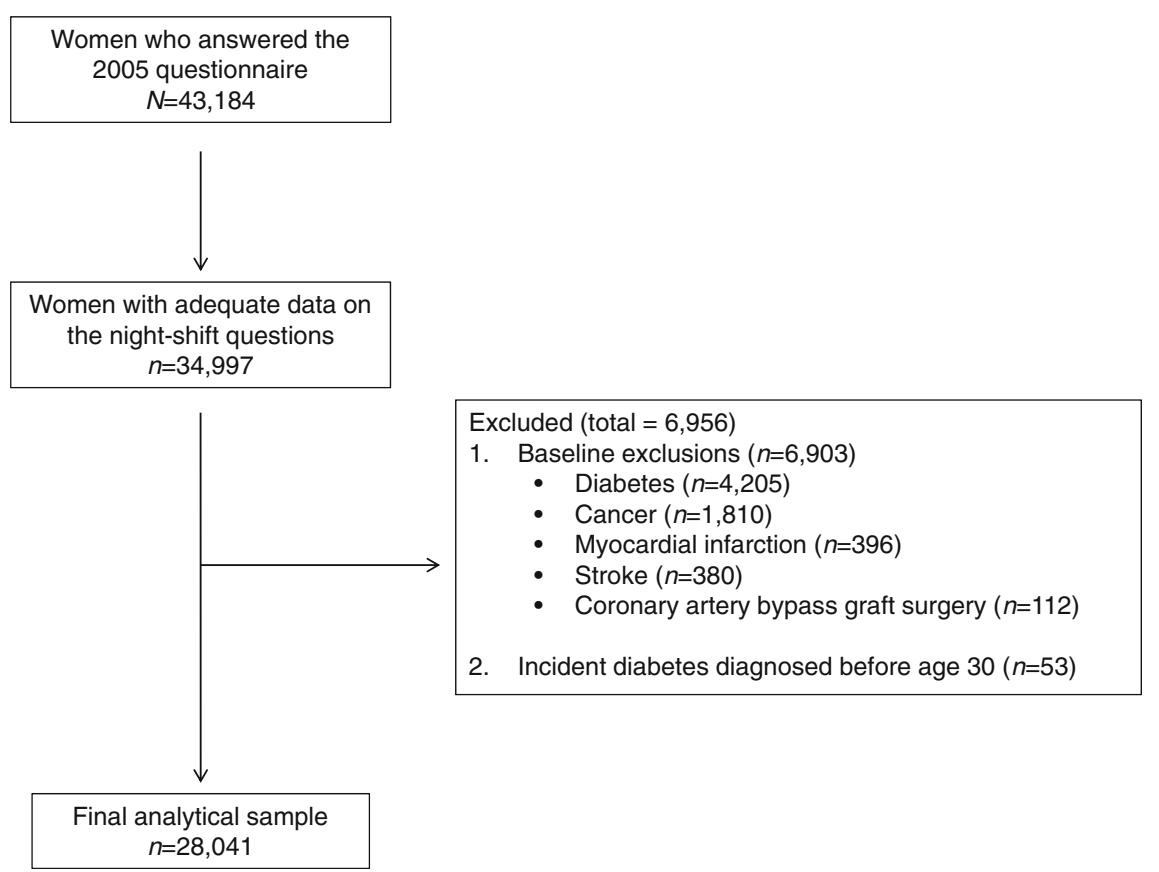

frequency questionnaires (FFQs) [26, 27]. Energy intake ( $\mathrm{kcal} /$ day [reported as $\mathrm{kJ} /$ day]) was estimated from the 1995 and 2001 FFQs using DIET*CALC software (version 1.4.1) from the National Cancer Institute, (Bethesda, MD, USA). Dietary patterns of vegetables/fruit and meat/fried food consumption were calculated from the 1995 and 2001 FFQs as previously described [28]. The vegetable/fruit dietary pattern was rich in whole grains, vegetables, fruit, legumes and fish and the meat/fried food pattern was rich in red meat, processed meat, french fries, fried chicken and added fat. First-degree family history of diabetes was ascertained in 1995 and 1999. Information on educational attainment was requested in the 1995 and 2003 questionnaires. We measured neighbourhood SES as previously described [29, 30]. Geocoding (Mapping Analytics, Rochester, NY, USA) was used to link participants' current addresses to 2000 US Census block groups. We then used factor analysis to calculate an index of neighbourhood SES.

Assessment of diabetes The presence of diabetes was ascertained through self-report on biennial follow-up questionnaires between 2005 and 2013. Cases were classified as incident if there was no report of a previous diagnosis. We conducted a validation study among a random sample of 656 women who reported a diagnosis of diabetes after 1995 (baseline of the BWHS cohort). Of the 293 women providing permission to contact their physician, completed questionnaires were returned by the physicians for 229 women and a diagnosis of diabetes was confirmed in 220 (96\%) of these cases. Of the nine participants without a confirmed diagnosis of type 2 diabetes, two had type 1 diabetes, one had the metabolic syndrome, one had steroid-induced diabetes, two had gestational diabetes and three did not have diabetes.

Undiagnosed diabetes To estimate the prevalence of undiagnosed diabetes in our cohort, we used data from blood samples that had been collected from BWHS participants in the last year. The BWHS received funding with which to request a blood draw from each participant for long-term storage, with every sample assayed for $\mathrm{HbA}_{1 \mathrm{c}}$. Samples were drawn at Quest Diagnostics Patient Service Centers and processing and assays were performed at Quest Diagnostics Regional Laboratories. Of the 2,449 women who provided a sample in the first year of collection, 1,873 had never reported diabetes. Among these 1,873 women, $120(6.4 \%)$ had $\mathrm{HbA}_{1 \mathrm{c}}$ levels of $6.5 \%(47.5 \mathrm{mmol} / \mathrm{mol})$ or higher (ESM Table 2) (i.e. meeting the $\mathrm{HbA}_{1 \mathrm{c}}$ criteria of the International Expert Committee appointed by the ADA, the EAS D and the International Diabetes Federation) [31].

Statistical analysis Person-years were measured from baseline (2005) until the diagnosis of type 2 diabetes, loss to follow-up, death or end of follow-up in 2013, whichever came first. We used Cox proportional hazards regression stratified by age and questionnaire cycle to calculate HRs and $95 \%$ CIs for the association of number of years of night-shift work with incident type 2 diabetes. We used the Andersen-Gill approach [32] to update time-varying exposures and covariates over follow-up.

In the basic multivariate model, we adjusted for age, questionnaire cycle, first-degree family history of diabetes, education ( $\leq 12,13-15,16, \geq 17$ years) and quintiles of the 
neighbourhood SES index. Next we added a group of lifestyle factors (vigorous physical activity [h/week], smoking [never smoked, past smoker, current smoker], alcohol drinking [never drank, past drinker, current drinker], dietary energy intake [ $\mathrm{kcal} /$ day, reported as $\mathrm{kJ} /$ day], vegetable/fruit and meat/fried food dietary pattern scores [continuous], regular coffee consumption [never, $<1 \mathrm{cup} / \mathrm{month}, 1 \mathrm{cup} / \mathrm{month}$ to $6 \mathrm{cups} /$ week, 1 , $2-3, \geq 4$ cups/day], decaffeinated coffee consumption [never to $<1 \mathrm{cup} / \mathrm{month}, 1 \mathrm{cup} / \mathrm{month}$ to $6 \mathrm{cups} / \mathrm{week}$, $1, \geq 2 \mathrm{cups} /$ day], regular soda consumption $[<1 \mathrm{cup} /$ month, 1-7 cups/month, 2-6 cups/week, 1, $\geq 2$ cups/day] and diet soda consumption $[<1$ cup/month, $1-7$ cups/month, 2-6 cups/week, $1, \geq 2$ cups/day]). We then compared results without and with adjustment for BMI $\left(<25,25-29,30-34,35-39, \geq 40 \mathrm{~kg} / \mathrm{m}^{2}\right)$ to assess how much of the association was explained by BMI. We performed tests for trend across categories of the number of years of night-shift work by using the median value for each of the night-shift work categories. We also conducted BMI-stratified (non-obese, BMI $<30 \mathrm{~kg}$ / $\mathrm{m}^{2}$; obese, BMI $\left.\geq 30 \mathrm{~kg} / \mathrm{m}^{2}\right)$ and age-stratified $(<50$ and $\geq 50$ years) analyses to assess potential effect modification by obesity and age. We controlled for BMI as a continuous variable in the BMI-stratified analysis.

\section{Results}

Table 1 shows baseline characteristics of the participants by categories of number of years of night-shift work. Of the 28,041 women included in the study, $21 \%$ had worked the night shift for $1-2$ years, $11 \%$ had worked the night shift for 3-9 years and 5\% had worked the night shift for $\geq 10$ years. Compared with the group who had never worked the night shift, the group that worked it for $\geq 10$ years was older, had a higher mean BMI and energy intake and more frequently had a family history of diabetes. They also had a higher frequency of smoking and consumed more coffee and soda. In addition, the group who had worked on the night shift for $\geq 10$ years also had lower levels of alcohol use, education, exercise and healthy dietary patterns and more frequently lived in neighbourhoods within the lowest quintile of SES.

Over 189,710 person-years of follow-up there were 1,786 cases of incident diabetes (Table 2). In a multivariate model without adjustment for lifestyle factors or BMI, the HR increased as the duration of night-shift work increased ( $p$-trend $<0.0001)$, with an HR $(95 \%$ CI) of $1.42(1.19,1.70)$ for $\geq 10$ years of working relative to never working the night shift. Adjustment for lifestyle factors and BMI attenuated the rate ratios, though a trend of increasing risk with more years of night-shift work persisted ( $p$-trend $=0.02$ ). Among the group

Table 1 Age-adjusted baseline (2005) characteristics by number of years of night-shift work ${ }^{\mathrm{a}}$

\begin{tabular}{|c|c|c|c|c|}
\hline \multirow[t]{2}{*}{ Characteristic } & \multicolumn{4}{|c|}{ Night-shift work category } \\
\hline & Never & $1-2$ years & $3-9$ years & $\geq 10$ years \\
\hline Number of women & 17,722 & 5,791 & 3,149 & 1,379 \\
\hline Mean age, years & 47.5 & 46.9 & 47.8 & 50.9 \\
\hline Mean BMI, kg/m² & 29.0 & 29.9 & 30.2 & 30.6 \\
\hline Mean energy intake, $\mathrm{kJ} /$ day & 6,004 & 6,280 & 6,569 & 6,707 \\
\hline Family history of diabetes, $\%$ & 34 & 36 & 37 & 41 \\
\hline Current smokers, $\%$ & 9 & 12 & 14 & 13 \\
\hline Current alcohol drinkers, $\%$ & 26 & 25 & 25 & 23 \\
\hline Regular coffee consumption $>1$ cup/day, $\%$ & 8 & 9 & 11 & 11 \\
\hline Decaffeinated coffee consumption $>1$ cup/day, $\%$ & 2 & 2 & 2 & 1 \\
\hline Regular soda consumption $>1$ cup/day, $\%$ & 5 & 6 & 7 & 9 \\
\hline Diet soda consumption $>1$ cup/day, $\%$ & 2 & 1 & 2 & 2 \\
\hline Education $\leq 12$ years, $\%$ & 10 & 13 & 14 & 18 \\
\hline Vigorous exercise $\geq 5 \mathrm{~h} /$ week, $\%$ & 9 & 7 & 9 & 8 \\
\hline \multicolumn{5}{|l|}{ Dietary patterns, $\%$} \\
\hline Fifth quintile of vegetable/fruit consumption (healthiest) & 20 & 19 & 18 & 18 \\
\hline Fifth quintile of meat/fried food consumption (unhealthiest) & 19 & 21 & 21 & 22 \\
\hline \multicolumn{5}{|l|}{ Neighbourhood SES, \% } \\
\hline First quintile (poorest neighbourhood) & 17 & 20 & 22 & 24 \\
\hline Fifth quintile (wealthiest neighbourhood) & 21 & 16 & 14 & 12 \\
\hline
\end{tabular}

${ }^{a}$ All of the characteristics vary significantly across years of shift work categories at the $\alpha=0.05$ level 
Table 2 Association of night-shift work with incidence of type 2 diabetes in the BWHS, 2005-2013

\begin{tabular}{|c|c|c|c|c|c|c|}
\hline \multirow[t]{2}{*}{ Model } & \multicolumn{4}{|c|}{ Night-shift work category } & \multirow[t]{2}{*}{ Trend test $p$ value } & \multirow{2}{*}{$\begin{array}{l}\text { Ever worked night shift, } \\
\text { HR }(95 \% \mathrm{CI})\end{array}$} \\
\hline & Never & $1-2$ years & $3-9$ years & $\geq 10$ years & & \\
\hline Cases/person-years & $1,014 / 120,899$ & $399 / 39,095$ & $235 / 20,817$ & $138 / 8,899$ & & $772 / 68,811$ \\
\hline Basic multivariate $^{\mathrm{a}}$ & 1.00 (reference) & $1.17(1.04,1.31)$ & $1.23(1.06,1.41)$ & $1.42(1.19,1.70)$ & $<0.0001$ & $1.22(1.11,1.34)$ \\
\hline+ Lifestyle factors $^{\mathrm{b}}$ & 1.00 (reference) & $1.14(1.01,1.28)$ & $1.18(1.02,1.36)$ & $1.35(1.13,1.62)$ & 0.0007 & $1.18(1.08,1.30)$ \\
\hline$+\mathrm{BMI}$ & 1.00 (reference) & $1.09(0.97,1.22)$ & $1.11(0.96,1.28)$ & $1.23(1.03,1.47)$ & 0.022 & $1.12(1.01,1.23)$ \\
\hline
\end{tabular}

${ }^{\text {a }}$ Basic covariates: age, questionnaire cycle, family history of diabetes, education and neighbourhood SES

${ }^{\mathrm{b}}$ Lifestyle factors: vigorous activity levels, smoking, alcohol, energy intake, dietary pattern and coffee, decaffeinated coffee, soda and diet soda consumption

with the longest duration of night-shift work there was an HR $(95 \% \mathrm{CI})$ of $1.23(1.03,1.47)$. The HR $(95 \% \mathrm{CI})$ for ever vs never having worked the night shift was $1.22(1.11,1.34)$, and this remained significant after adjustment for lifestyle factors and BMI $(1.12$ [1.01, 1.23]).

Stratified analyses showed that the association between night-shift work and diabetes did not significantly vary by obesity status $(p$-interaction $=0.12)$ (Table 3$)$. On the other hand, the association was stronger in younger women than in older women. Working night shifts for $\geq 10$ years relative to never working the night shift was associated with a $39 \%$ higher risk of diabetes among women aged $<50$ years compared with just $17 \%$ higher risk in older women aged $\geq 50$ years (Table 3$)(p$-interaction $=0.028)$.

\section{Discussion}

In this large prospective cohort study of African-American women, we found that an increasing number of years of nightshift work was associated with a greater risk of incident type 2 diabetes, even after adjustment for lifestyle factors and BMI. Those with the longest duration of night-shift work had a $23 \%$ increased incidence of type 2 diabetes. The association was stronger in women aged less than 50 years than in older women.

Our findings are consistent with the few epidemiological studies of which we are aware that examine the impact of increasing duration of shift work on diabetes risk. In a crosssectional telephone survey of 1,111 retired older adults in

Table 3 Association of night-shift work with incidence of type 2 diabetes by obesity and age in the BWHS, 2005-2013

\begin{tabular}{|c|c|c|c|c|c|c|}
\hline \multirow[t]{2}{*}{ Model } & \multicolumn{4}{|c|}{ Night-shift work category } & \multirow[t]{2}{*}{ Trend test $p$ value } & \multirow{2}{*}{$\begin{array}{l}\text { Ever worked night } \\
\text { shift, HR }(95 \% \mathrm{CI}\end{array}$} \\
\hline & Never & $1-2$ years & $3-9$ years & $\geq 10$ years & & \\
\hline \multicolumn{7}{|l|}{ Non-obese ${ }^{b}$} \\
\hline Cases/person-years & $333 / 73,933$ & $125 / 21,472$ & $48 / 10,993$ & $32 / 4,325$ & & $205 / 36,790$ \\
\hline Multivariate model $^{\mathrm{a}}$ & 1.00 (reference) & $1.17(0.95,1.45)$ & $0.81(0.60,1.10)$ & $1.16(0.80,1.68)$ & 0.79 & $1.06(0.89,1.27)$ \\
\hline \multicolumn{7}{|l|}{ Obese $^{b}$} \\
\hline Cases/person-years & $653 / 45,405$ & $261 / 17,054$ & $174 / 9,439$ & $98 / 4,364$ & & $533 / 30,857$ \\
\hline 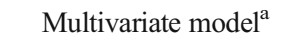 & 1.00 (reference) & $1.05(0.91,1.21)$ & $1.20(1.01,1.42)$ & $1.23(0.99,1.53)$ & 0.029 & $1.12(1.00,1.26)$ \\
\hline \multicolumn{7}{|l|}{ Age $<50$ years $^{\mathrm{c}}$} \\
\hline Cases/person-years & $339 / 62,394$ & $163 / 21,205$ & $100 / 10,433$ & $40 / 3,253$ & & $303 / 34,891$ \\
\hline Multivariate model $^{\mathrm{a}}$ & 1.00 (reference) & $1.19(0.99,1.44)$ & $1.38(1.10,1.73)$ & $1.39(0.99,1.94)$ & 0.012 & $1.27(1.09,1.49)$ \\
\hline \multicolumn{7}{|l|}{ Age $\geq 50$ years $^{\mathrm{c}}$} \\
\hline Cases/person-years & $675 / 58,505$ & $236 / 17,890$ & $135 / 10,384$ & $98 / 5,646$ & & $469 / 33,921$ \\
\hline 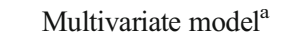 & 1.00 (reference) & $1.02(0.88,1.18)$ & $0.97(0.80,1.16)$ & $1.17(0.94,1.45)$ & 0.20 & $1.03(0.91,1.16)$ \\
\hline
\end{tabular}


Western Pennsylvania, the prevalence of diabetes was doubled in those with any history of night-shift work. Even after adjustment for BMI, there was increasing diabetes risk with increased exposure to the night shift; those having done more than 20 years of night-shift work had a twofold increased risk [33]. In contrast, an early NHS paper based on 356 cases of diabetes found that an association between increasing years of shift work and incident diabetes was explained away completely in a multivariable analysis that included BMI [18]. This study examined rotating night-shift work (3 nights/month in addition to days and evenings in that month). An updated analysis from the NHS included more than 177,000 women from NHS (older women, 6,165 incident diabetes cases) and NHS II (younger women, 3,961 cases) [17]. Over 20 years of follow-up, the authors found a positive association, which was attenuated but still present after adjustment for BMI. For example, female participants in the NHS who had done $10-19$ years and $\geq 20$ years of night-shift work had a pooled HR for incident diabetes of 1.40 ( $95 \%$ CI, 1.30, $1.51)$ and $1.58(1.43,1.74)$, respectively. Adjustment for BMI decreased the HR to 1.10 (95\% CI, 1.02, 1.18) and 1.24 (1.13, 1.37), respectively. In both models, there was a significant trend towards increasing diabetes risk with increasing years of shift work ( $p$-trend $<0.001$ ). Our results on the association of night-shift work with incident type 2 diabetes in a population of black women are consistent with those based on data from white women. In addition, our finding that adjustment for BMI substantially attenuated the relative risk, as in the NHS, indicates that BMI could be a major mediator for the observed association between night-shift work and incident diabetes. NHS investigators found that the relationship between nightshift work and diabetes was similar in younger and older women. In contrast, we found that the association between number of years of shift work and diabetes was stronger among younger women ( $<50$ years). This may be because the effect of shift work is more easily detected in those who are at lower risk of diabetes (i.e. younger women).

Even though lifestyle factors and BMI explained a major part of the association of shift work with incident diabetes, women with a long duration of shift work had an increased risk of diabetes after control for those factors, suggesting the presence of additional causal pathways. Shift work is associated with disrupted circadian rhythms and reduced total duration of sleep [34]. Similar to the effects of jet lag, which are short term, shift workers experience fatigue, sleepiness during scheduled awake periods and poor sleep during scheduled sleep periods [4]. These alterations in the normal sleep-wake cycle have profound effects on metabolism [6]. Leproult et al reported that circadian misalignment is associated with increased insulin resistance and inflammation, independent of sleep loss [35]. In another study, Scheer at al demonstrated that circadian misalignment leads to decreased leptin levels, increased glucose and insulin levels, increased mean arterial pressure and inversion of the normal diurnal cortisol secretion pattern [4]. The precise mechanisms by which these changes occur are still unclear. In animal models, circadian disruption in susceptible rats led to more rapid loss of beta cell function and increased beta cell apoptosis, resulting in decreased beta cell mass, decreased glucose-stimulated insulin secretion and accelerated development of diabetes [36]. Even after many years of night-shift work, circadian rhythms do not fully adjust to the shifted sleep-wake cycle [37]. The metabolic effects of long-term shift work likely underlie a part of the association with diabetes that we and others describe and that strengthens with years of exposure to sleep disruption.

The present study has several strengths, including its large size, high rates of follow-up, prospective data on shift work and on many important potential confounders and a high-risk population group not previously studied with regard to shift work and diabetes. However, we do note some limitations. We relied on self-reported measures at one point in time of cumulative exposure to night-shift work and did not have data on specific schedules or dates, which introduces the possibility of exposure misclassification. We did not collect data on shift work status subsequently. We also relied on a self-reported diabetes diagnosis rather than on clinical data. However, in an earlier validation study among 229 participants whose physicians returned a completed questionnaire, we found $96 \%$ of self-reported diabetes cases to be confirmed in the medical record. Prevalence of undiagnosed diabetes in the BWHS $(6.4 \%)$ was similar to what has previously been reported in African-American women [22]. We found no major difference in prevalence of undiagnosed diabetes between night-shift workers $(6.1 \%)$ vs non-night-shift workers $(6.5 \%)(p=0.72$ for difference of proportions), or between women who answered the night-shift questions $(6.3 \%)$ vs women who did not answer the night-shift questions (6.9\%) ( $p=0.55$ for difference of proportions) (ESM Table 2). We estimate that the observed prevalence of undiagnosed diabetes in the BWHS, given non-differential misclassification between night-shift workers and non-night-shift workers, would result in an underestimation of about $5 \%$ of the true association of night-shift work with diabetes (ESM Methods). While we did find significant associations between night-shift work and diabetes, the true association may be stronger. A certain degree of selection bias is also possible given that not all of the women who responded to the 2005 questionnaire answered the nightshift questions. Although we are unable to quantify the degree of bias, the fact that women who did not answer the night-shift questions had similar characteristics regarding major risk factors for type 2 diabetes (i.e. age, BMI, family history of diabetes, diet and physical activity) (ESM Table 1) as well as similar prevalence of undiagnosed diabetes (ESM Table 2) compared with women who did answer the night-shift questions suggests that selection bias might have a minor effect in the present results. We cannot completely rule out the 
presence of residual confounding due to measurement error of covariates or failure to control for other confounders. With regard to BMI, a previous validation study found that selfreport of height and weight in the BWHS was highly accurate [25]. In addition, the association with night-shift work was present even among obese women. Also, previously reported associations of BMI [38] and behaviour variables [39] with diabetes in the BWHS suggest that our covariate measures capture biologically relevant information.

In summary, we found that African-American women undergoing long-duration night-shift work had a higher risk of incident diabetes. The fact that the association remained, though attenuated, after adjustment for lifestyle factors and BMI suggests that additional pathways such as disruption of the circadian system may be playing a role. In view of the high prevalence of shift work among workers in the USA $(35 \%$ among non-Hispanic blacks and $28 \%$ in non-Hispanic whites) [40], an increased diabetes risk among this group has important public health implications. There is a need for continued research into facilitating circadian adaptation to shift work [3] and consideration of avoiding shift work in favour of other work arrangements when possible [37].

Acknowledgements We thank the BWHS participants for their continuing participation in this research effort. We also thank E. Schernhammer (Department of Epidemiology, Harvard School of Public Health, Harvard, MA, USA) for her help in designing the questions on night-shift work.

Funding This work was supported by National Institute on Minority Health and Health Disparities (NIMHD) grant R01MD007015 and by National Cancer Institute (NCI) grant R01CA058420 and UM1CA164974. EARN is supported by grant 11SDG7390014 from the American Heart Association. Additionally, the material is based upon work or supported in part by the Department of Veterans Affairs, Veterans Health Administration, Office of Research and Development.

The views expressed in this article are those of the authors and do not necessarily reflect the position or policy of the Department of Veterans Affairs, the US government, the NIMHD, the NCI, the National Institutes of Health or the American Heart Association.

Duality of interest The authors declare that there are no conflicts of interest associated with this manuscript.

Contribution statement All authors made substantial contributions to one or more of the following: the study conception and design; acquisition of data and analysis and interpretation of the data. All authors contributed to drafting and/or revising the article critically for important intellectual content and all authors provided their final approval of the version to be published. EARN is the guarantor of this work.

\section{References}

1. Beers TM (2000) Flexible schedules and shift work: replacing the 9to-5 workday. Mon Lab Rev 123:33

2. Hastings MH, Maywood ES, Reddy AB (2008) Two decades of circadian time. J Neuroendocrinol 20:812-819
3. Sack RL, Auckley D, Auger RR et al (2007) Circadian rhythm sleep disorders: part I, basic principles, shift work and jet lag disorders. An American Academy of Sleep Medicine review. Sleep 30:1460-1483

4. Scheer FA, Hilton MF, Mantzoros CS, Shea SA (2009) Adverse metabolic and cardiovascular consequences of circadian misalignment. Proc Natl Acad Sci U S A 106:4453-4458

5. Puttonen S, Harma M, Hublin C (2010) Shift work and cardiovascular disease - pathways from circadian stress to morbidity. Scand J Work Environ Health 36:96-108

6. Eckel-Mahan K, Sassone-Corsi P (2013) Metabolism and the circadian clock converge. Physiol Rev 93:107-135

7. Vyas MV, Garg AX, Iansavichus AV et al (2012) Shift work and vascular events: systematic review and meta-analysis. BMJ 345:e4800

8. De Bacquer D, Van Risseghem M, Clays E, Kittel F, De Backer G, Braeckman L (2009) Rotating shift work and the metabolic syndrome: a prospective study. Int J Epidemiol 38:848-854

9. Pietroiusti A, Neri A, Somma G et al (2010) Incidence of metabolic syndrome among night-shift healthcare workers. Occup Environ Med 67:54-57

10. Lin YC, Hsiao TJ, Chen PC (2009) Persistent rotating shift-work exposure accelerates development of metabolic syndrome among middle-aged female employees: a five-year follow-up. Chronobiol Int 26:740-755

11. Esquirol Y, Bongard V, Mabile L, Jonnier B, Soulat JM, Perret B (2009) Shift work and metabolic syndrome: respective impacts of job strain, physical activity, and dietary rhythms. Chronobiol Int 26:544 559

12. Karlsson B, Knutsson A, Lindahl B (2001) Is there an association between shift work and having a metabolic syndrome? Results from a population based study of 27,485 people. Occup Environ Med 58: 747-752

13. Antunes LC, Levandovski R, Dantas G, Caumo W, Hidalgo MP (2010) Obesity and shift work: chronobiological aspects. Nutr Res Rev 23:155-168

14. Kim MJ, Son KH, Park HY et al (2013) Association between shift work and obesity among female nurses: Korean Nurses' Survey. BMC Public Health 13:1204

15. van Amelsvoort LG, Schouten EG, Kok FJ (1999) Duration of shiftwork related to body mass index and waist to hip ratio. Int J Obes Relat Metab Disord 23:973-978

16. Eriksson AK, van den Donk M, Hilding A, Ostenson CG (2013) Work stress, sense of coherence, and risk of type 2 diabetes in a prospective study of middle-aged Swedish men and women. Diabetes Care 36:2683-2689

17. Pan A, Schernhammer ES, Sun Q, Hu FB (2011) Rotating night shift work and risk of type 2 diabetes: two prospective cohort studies in women. PLoS Med 8:e1001141

18. Kroenke CH, Spiegelman D, Manson J, Schernhammer ES, Colditz GA, Kawachi I (2007) Work characteristics and incidence of type 2 diabetes in women. Am J Epidemiol 165:175-183

19. Morikawa Y, Nakagawa H, Miura K et al (2005) Shift work and the risk of diabetes mellitus among Japanese male factory workers. Scand J Work Environ Health 31:179-183

20. Suwazono Y, Sakata K, Okubo Y et al (2006) Long-term longitudinal study on the relationship between alternating shift work and the onset of diabetes mellitus in male Japanese workers. J Occup Environ Med 48:455-461

21. Gan Y, Yang C, Tong X, et al (2014) Shift work and diabetes mellitus: a meta-analysis of observational studies. Occup Environ Med

22. Cowie CC, Rust KF, Byrd-Holt DD et al (2006) Prevalence of diabetes and impaired fasting glucose in adults in the U.S. population: National Health And Nutrition Examination Survey 1999-2002. Diabetes Care 29:1263-1268

23. Flegal KM, Carroll MD, Kit BK, Ogden CL (2012) Prevalence of obesity and trends in the distribution of body mass index among US adults, 1999-2010. JAMA 307:491-497 
24. Rosenberg L, Adams-Campbell L, Palmer JR (1995) The Black Women's Health Study: a follow-up study for causes and preventions of illness. J Am Med Wom Assoc 50:56-58

25. Carter-Nolan PL, Adams-Campbell LL, Makambi K, Lewis S, Palmer JR, Rosenberg L (2006) Validation of physical activity instruments: Black Women's Health Study. Ethn Dis 16:943-947

26. Kumanyika SK, Mauger D, Mitchell DC, Phillips B, SmiciklasWright H, Palmer JR (2003) Relative validity of food frequency questionnaire nutrient estimates in the Black Women's Health Study. Ann Epidemiol 13:111-118

27. Block G, Hartman AM, Naughton D (1990) A reduced dietary questionnaire: development and validation. Epidemiology 1:58-64

28. Boggs DA, Palmer JR, Spiegelman D, Stampfer MJ, AdamsCampbell LL, Rosenberg L (2011) Dietary patterns and 14-y weight gain in African American women. Am J Clin Nutr 94:86-94

29. Krishnan S, Cozier YC, Rosenberg L, Palmer JR (2010) Socioeconomic status and incidence of type 2 diabetes: results from the Black Women's Health Study. Am J Epidemiol 171:564-570

30. Coogan PF, Cozier YC, Krishnan S et al (2010) Neighborhood socioeconomic status in relation to 10 -year weight gain in the Black Women's Health Study. Obesity (Silver Spring) 18:2064-2065

31. (2009) International Expert Committee report on the role of the A1C assay in the diagnosis of diabetes. Diabetes Care 32: 1327-1334

32. Andersen PK, Gill RD (1982) Cox's regression model for counting processes: a large sample study. Ann Stat 10:1100-1120
33. Axelsson J, Puttonen S (2012) Night shift work increases the risk for type 2 diabetes. Evid Based Med 17:193-194

34. Pilcher JJ, Lambert BJ, Huffcutt AI (2000) Differential effects of permanent and rotating shifts on self-report sleep length: a metaanalytic review. Sleep 23:155-163

35. Leproult R, Holmback U, Van Cauter E (2014) Circadian misalignment augments markers of insulin resistance and inflammation, independently of sleep loss. Diabetes 63:1860-1869

36. Gale JE, Cox HI, Qian J, Block GD, Colwell CS, Matveyenko AV (2011) Disruption of circadian rhythms accelerates development of diabetes through pancreatic beta-cell loss and dysfunction. J Biol Rhythm 26:423-433

37. Drake CL, Roehrs T, Richardson G, Walsh JK, Roth T (2004) Shift work sleep disorder: prevalence and consequences beyond that of symptomatic day workers. Sleep 27:1453-1462

38. Krishnan S, Rosenberg L, Djousse L, Cupples LA, Palmer JR (2007) Overall and central obesity and risk of type 2 diabetes in U.S. black women. Obesity (Silver Spring) 15:1860-1866

39. Krishnan S, Rosenberg L, Palmer JR (2009) Physical activity and television watching in relation to risk of type 2 diabetes: the Black Women's Health Study. Am J Epidemiol 169:428-434

40. Alterman T, Luckhaupt SE, Dahlhamer JM, Ward BW, Calvert GM (2013) Prevalence rates of work organization characteristics among workers in the U.S.: data from the 2010 National Health Interview Survey. Am J Ind Med 56:647-659 